\title{
Kinase Suppressor of Ras 2
}

National Cancer Institute

\section{Source}

National Cancer Institute. Kinase Suppressor of Ras 2. NCI Thesaurus. Code C97222.

Kinase suppressor of Ras 2 (950 aa, 108 kDa) is encoded by the human KSR2 gene. This protein plays a role in both the localization and sequestration of mitogen-activated protein kinase kinase family members. 